\title{
Concentrated Sodium Bis(fluorosulfonyl)amide Aqueous Electrolyte Solutions for Electric Double-layer Capacitors
}

\author{
Yasuyuki KONDO, ${ }^{\mathrm{a}, *}$ Kohei MIYAZAKI, ${ }^{\mathrm{a}, \mathrm{b}}$ Yuko YOKOYAMA, ${ }^{\mathrm{c}}$ Yuto MIYAHARA, \\ Tomokazu FUKUTSUKA, ${ }^{d}$ and Takeshi $A B E^{a, b}$ \\ ${ }^{a}$ Hall of Global Environmental Research, Kyoto University, Nishikyo-ku, Kyoto 615-8510, Japan \\ ${ }^{b}$ Graduate School of Engineering, Kyoto University, Nishikyo-ku, Kyoto 615-8510, Japan \\ c Office of Society-Academia Collaboration for Innovation, Kyoto University, Nishikyo-ku, Kyoto 615-8510, Japan \\ d Graduate School of Engineering, Nagoya University, Furo-cho, Chikusa-ku, Nagoya 464-8603, Japan \\ *Corresponding author: yasuyuki.kondo@elech.kuic.kyoto-u.ac.jp
}

\section{ABSTRACT}

Here, highly concentrated sodium bis(fluorosulfonyl)amide ( $\mathrm{NaFSA}$ ) aqueous electrolytes were examined for the aqueous electrolytes of electric double-layer capacitors with wide potential window. Firstly, fundamental properties of electrolytes were investigated using conductivity measurements and Raman spectroscopy. During cyclic voltammetry of activated carbon electrodes, aluminum corrosion was observed for positive electrode side. After current collectors of positive electrodes were changed to titanium, capacitor reactions were confirmed for both of positive electrode and negative electrode sides in NaFSA aqueous electrolytes. In addition, resistances of activated carbon electrodes in NaFSA aqueous electrolytes were smaller than those in LiTFSA aqueous electrolytes.

(c) The Author(s) 2020. Published by ECSJ. This is an open access article distributed under the terms of the Creative Commons Attribution Non-Commercial Share Alike 4.0 License (CC BY-NC-SA, http://creativecommons.org/licenses/by-nc-sa/4.0/), which permits non-commercial reuse, distribution, and reproduction in any medium by share-alike, provided the original work is properly cited. For permission for commercial reuse, please email to the corresponding author. [DOI: 10.5796/electrochemistry.20-63001] Uploading "PDF file created by publishers" to institutional repositories or public websites is not permitted by the copyright license agreement.

\section{Keywords : Concentrated Aqueous Solutions, Conductivity, Activated Carbon}

\section{Introduction}

Electric double-layer capacitors (EDLCs) are energy storage devices with high power and widely used with lithium-ion batteries. ${ }^{1,2}$ As for the electrolytes of EDLCs, organic electrolytes and aqueous electrolytes have been examined. ${ }^{3}$ Organic electrolytes are widely used for EDLCs because potential window of organic electrolytes is larger than that of aqueous electrolytes, which increases the operation voltage and energy densities of EDLCs. On the other hand, aqueous type EDLCs are superior to non-aqueous type EDLCs in terms of rate capabilities or specific capacitances of activated carbon electrodes. However, the voltage of aqueous type EDLCs are lower than that of non-aqueous type EDLCs due to the limitation of potential window of water. Hence, there is a need to expand the potential window of aqueous electrolytes for EDLCs.

Recently, applying highly concentrated aqueous electrolytes has been reported as the strategy to enlarge the potential window of aqueous electrolytes. ${ }^{4-6}$ Aqueous electrolytes with high concentration of lithium salts, called as "Water-in-salts" melts", 5 were firstly reported as electrolyte solutions of high voltage aqueous lithium-ion batteries. In these neutral highly concentrated aqueous electrolytes, the potential window is expanded due to low activities of water, local $\mathrm{pH}$ change, low HOMO level of water or formation of surface films on electrodes. ${ }^{4-6}$ Highly concentrated electrolytes have been also examined as electrolyte solutions in aqueous EDLCs. ${ }^{7-10}$ The operation voltage of EDLCs using highly concentrated aqueous electrolytes was actually expanded. However, the rate capabilities of EDLCs using concentrated lithium bis(trifluoromethanesulfonyl) amide (LiTFSA) aqueous electrolytes were not high because of low ionic conductivities of the electrolytes. ${ }^{7}$ Therefore, nanostructured carbon electrodes with short diffusion length through pores were necessary. ${ }^{9}$ Concentrated sodium salt based aqueous electrolytes were also reported as electrolytes for EDLCs. ${ }^{8}$ The ionic conductivities of concentrated sodium perchlorate $\left(\mathrm{NaClO}_{4}\right)$ aqueous electrolytes are high and the power density of EDLCs using concentrated $\mathrm{NaClO}_{4}$ aqueous electrolytes seems to be relatively high. On the other hand, the coulombic efficiencies of these aqueous EDLCs were low under the condition of high operation voltage. Therefore, it is still necessary to explore the concentrated aqueous electrolytes with high conductivities and high coulombic efficiencies of EDLCs.

Here, we examined the feasibility of concentrated sodium bis(fluorosulfonyl) amide (NaFSA) aqueous electrolytes for EDLCs. The solubility of FSA salts is very high compared with other salts. ${ }^{11}$ Actually our group reported the potential window has been expanded in concentrated NaFSA aqueous electrolytes, which enabled electrochemical FSA anion intercalation into graphite. ${ }^{12}$ In addition, conductivities of sodium salt based electrolytes seems to be higher than those of lithium salt based electrolytes due to the week lewis acidity of sodium-ion. Hence, it is expected that EDLCs using concentrated NaFSA aqueous electrolytes can show good rate capability and large operation voltage.

\section{Experimental}

Electrochemical measurements were carried out using a threeelectrode cell. Activated carbons were produced by Panasonic and composite electrodes were used as working electrodes. The geometric area of working electrodes being in contact with electrolytes were $0.48 \mathrm{~cm}^{2}$. The current collectors of composite electrodes were aluminum foils or titanium foils. $\mathrm{Ag} / \mathrm{AgCl}$ electrodes were used as reference electrodes and platinum mesh 

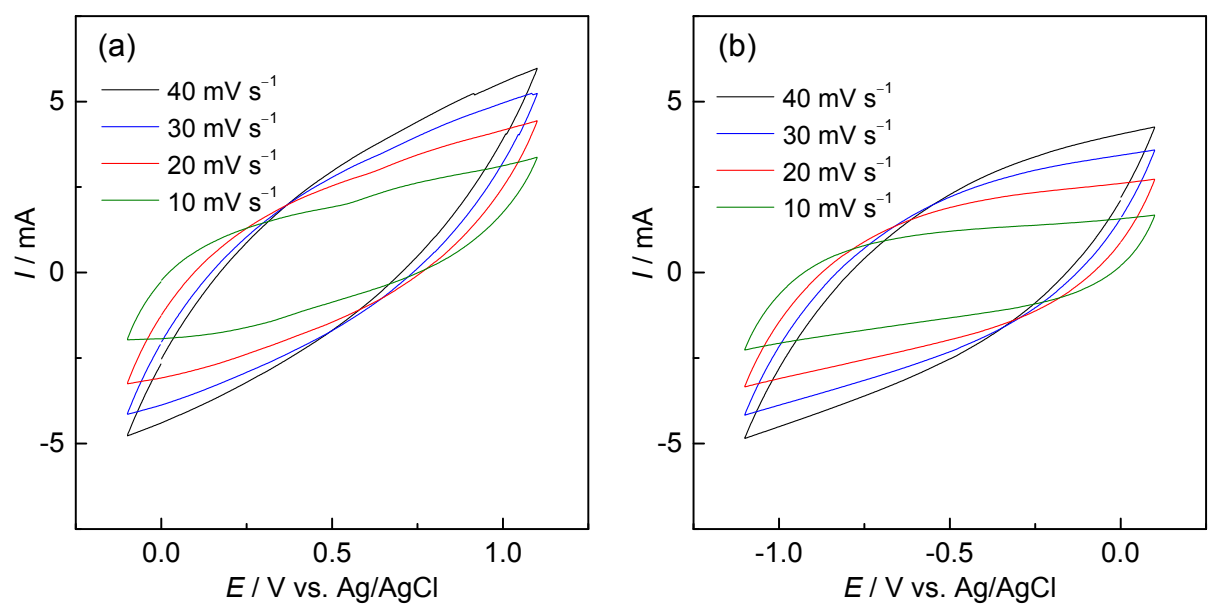

Figure 1. Cyclic voltammograms of activated carbon composite electrode for (a) positive electrode side and (b) negative electrode side in $19 \mathrm{~mol} \mathrm{~kg}^{-1}$ NaFSAaq. at the various scan rates.

electrodes were used as counter electrodes. Electrolyte solutions were aqueous solutions of $19 \mathrm{~mol} \mathrm{~kg}^{-1} \mathrm{NaFSA}, 18 \mathrm{~mol} \mathrm{~kg}^{-1} \mathrm{NaClO}_{4}$ or $21 \mathrm{~mol} \mathrm{~kg}^{-1}$ LiTFSA. Hereafter, all potentials are referred to as vs. $\mathrm{Ag} / \mathrm{AgCl}$. Cyclic voltammetry was conducted between $-0.1 \mathrm{~V}$ and $1.1 \mathrm{~V}$ (positive electrode side) or between $0.1 \mathrm{~V}$ and $-1.1 \mathrm{~V}$ (negative electrode side), and the scan rate was set at 40,30, 20 or $10 \mathrm{mV} \mathrm{s}^{-1}$. Charge-discharge measurements were conducted between $-0.1 \mathrm{~V}$ and $1.2 \mathrm{~V}$ or $0.1 \mathrm{~V}$ and $-1.2 \mathrm{~V}$ at various currents. Current values were decided to be currents for $200 \mathrm{~s}$ charge or discharge in aqueous solutions of $19 \mathrm{~mol} \mathrm{~kg}^{-1} \mathrm{NaFSA}$. Capacitances were calculated according to the following equation:

$$
C=\frac{I t}{S \Delta V}
$$

where $\mathrm{C}$ is the electric double-layer capacitance $\left(\mathrm{F} \mathrm{cm}^{-2}\right)$, I the current (A), $\mathrm{t}$ the positive or negative duration time (s), $\mathrm{S}$ the geometric area of working electrode $\left(\mathrm{cm}^{2}\right)$, and $\Delta \mathrm{V}$ is the potential change during charge-discharge processes. Raman spectroscopy and conductivity measurements were used for characterization of electrolyte properties. Electrochemical measurements were carried out using Solartron1470E+1255 (Solartron Analytical) and HJ1001SD8 (HOKUTO-DENKO). To investigate electrochemical stability window of $19 \mathrm{~mol} \mathrm{~kg}^{-1} \mathrm{NaFSAaq}$., cyclic voltammetry was conducted using the titanium foil working electrode between $-1.5 \mathrm{~V}$ and $1.5 \mathrm{~V}$ at the scan rate of $1 \mathrm{mV} \mathrm{s}^{-1}$.

\section{Results and Discussion}

\subsection{Physicochemical properties of electrolytes}

Figure S1 shows the Raman spectra of $19 \mathrm{~mol} \mathrm{~kg}^{-1} \mathrm{NaFSAaq}$., $18 \mathrm{~mol} \mathrm{~kg}^{-1} \mathrm{NaClO}_{4}$ aq. and $21 \mathrm{~mol} \mathrm{~kg}^{-1}$ LiTFSAaq. The narrow bands ascribed to $\mathrm{OH}$ stretching modes of water ${ }^{5}$ at around $3570 \mathrm{~cm}^{-1}$ were observed in all Raman spectra. These Raman spectra indicated that the amounts of free water in concentrated sodium salts aqueous electrolytes were as small as in concentrated LiTFSA aqueous electrolytes. The conductivity of $19 \mathrm{~mol} \mathrm{~kg}^{-1}$ NaFSAaq. was $37 \mathrm{mS} \mathrm{cm}^{-1}$, which was lower than that of $18 \mathrm{~mol} \mathrm{~kg}^{-1} \mathrm{NaClO}_{4}$ aq. $\left(115 \mathrm{mS} \mathrm{cm}^{-1}\right)$ but higher than that of $21 \mathrm{~mol} \mathrm{~kg}^{-1}$ LiTFSAaq. $\left(10 \mathrm{mS} \mathrm{cm}^{-1}\right){ }^{6}$ Figure S2 shows the cyclic voltammogram $(\mathrm{CV})$ of the titanium foil electrode in the aqueous solution of $19 \mathrm{~mol} \mathrm{~kg}^{-1} \mathrm{NaFSA}$. From the cyclic voltammorgram, the electrochemical stability window was determined to be around $2.7 \mathrm{~V}(-1.3 \mathrm{~V}-1.4 \mathrm{~V})$.

\subsection{Capacitor properties of activated carbon electrodes}

Figure 1 shows the CVs of activated carbon electrodes using aluminum current collectors in aqueous solutions of $19 \mathrm{~mol} \mathrm{~kg}^{-1}$ NaFSA ((a) positive electrode and (b) negative electrode side). In the CVs of negative electrode side, the shape of CV curves got close to quadrilateral as the scan rates decreased. This scan rate dependence indicated capacitor reaction of ion adsorption/desorption on activated carbons. On the other hand, in the CVs of positive electrode side, the shape of $\mathrm{CV}$ curves indicated the faradic reaction, which seemed to be due to severe aluminum corrosion. Therefore, current collectors should be changed from aluminum to titanium for the positive electrode side to prevent corrosion.

Figure 2 shows the charge-discharge curves of activated carbon electrodes on $\mathrm{Ti}$ ((a) positive electrode side) and on $\mathrm{Al}$ ((b) negative electrode side) foils in aqueous solutions of $19 \mathrm{~mol} \mathrm{~kg}^{-1} \mathrm{NaFSA}$ and $21 \mathrm{~mol} \mathrm{~kg}^{-1}$ LiTFSA. The capacitor reaction seemed to proceed without severe faradic reaction to the potential of $1.2 \mathrm{~V}$ and $-1.2 \mathrm{~V}$ for positive and negative electrode side in NaFSAaq., respectively. These cut-off potentials might be equivalent to the full cell cut-off voltage of $2.4 \mathrm{~V}$. Charge-discharge curves indicated the existence of faradic reactions like reaction on current collectors or water splitting. Surface treatments to prevent irreversible reaction are necessary in the future. During the charge-discharge measurements of activated carbon electrodes in 18 mol kg ${ }^{-1} \mathrm{NaClO}_{4}$ aq., aluminum corrosion was severe even for negative electrode side. Hence, aluminum current collectors can be applied to negative electrodes of aqueous EDLCs using NaFSAaq. with appropriate surface treatment. As shown in Fig. 2, the capacitor reaction also proceeded in $21 \mathrm{~mol} \mathrm{~kg}^{-1}$ LiTFSAaq., but the large resistance were observed compare with the resistance in $19 \mathrm{~mol} \mathrm{~kg}^{-1}$ NaFSAaq. The capacitances of activated carbon electrodes in $19 \mathrm{~mol} \mathrm{~kg}^{-1} \mathrm{NaFSAaq}$. were around $0.15 \mathrm{~F} \mathrm{~cm}^{-2}$ under the current density of $1 \mathrm{~mA} \mathrm{~cm}^{-2}$ and $0.34 \mathrm{~F} \mathrm{~cm}^{-2}$ under the current density of $1.7 \mathrm{~mA} \mathrm{~cm}^{-2}$ for positive and negative electrode side, respectively. The capacitances in $21 \mathrm{~mol} \mathrm{~kg}^{-1}$ LiTFSAaq. were around $0.085 \mathrm{~F} \mathrm{~cm}^{-2}$ under the current density of $1 \mathrm{~mA} \mathrm{~cm}^{-2}$ and $0.23 \mathrm{~F} \mathrm{~cm}^{-2}$ under the current density of $1.7 \mathrm{~mA} \mathrm{~cm}^{-2}$ for positive and negative electrode side, respectively. Hence, the capacitances and rate capabilities of EDLCs using concentrated NaFSA aqueous solutions should be high probably because of faradic reactions or high ionic conductivities.

\section{Conclusions}

Firstly, physicochemical properties of concentrated aqueous electrolytes were investigated using conductivity measurements and Raman spectroscopy. Raman spectra suggested the amounts of free water molecules are small in concentrated sodium salts aqueous electrolytes. The conductivities of concentrated NaFSA aqueous 

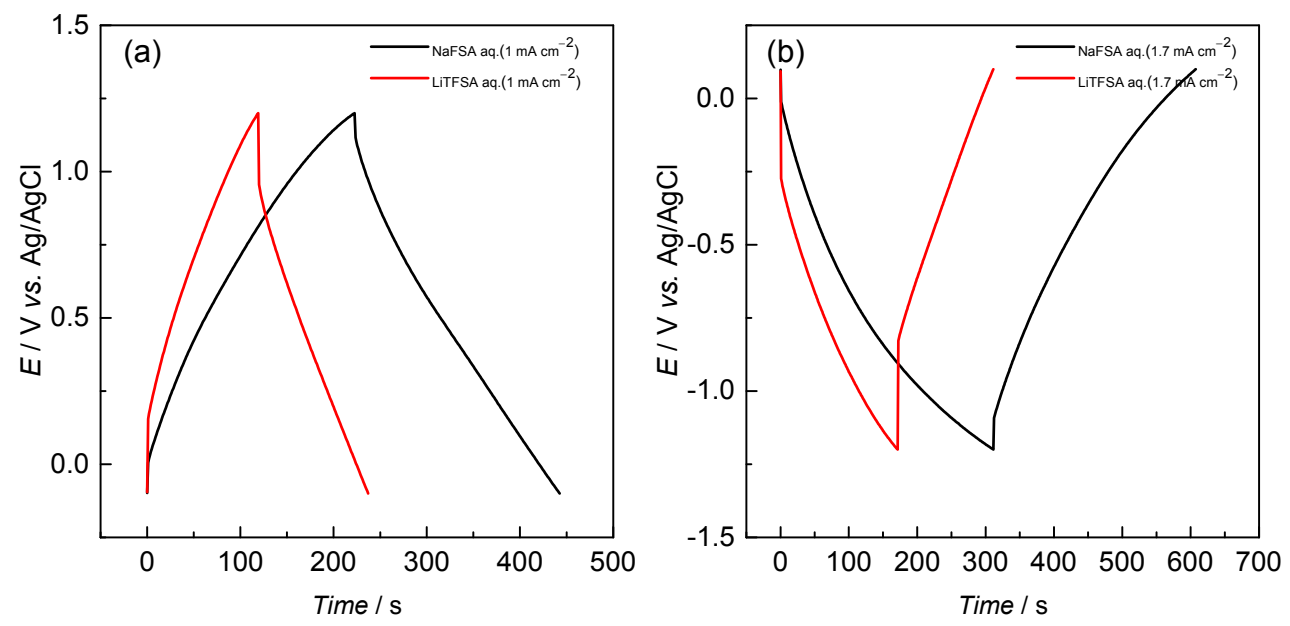

Figure 2. Charge-discharge curves of activated carbon composite electrode for (a) positive electrode side and (b) negative electrode side in $19 \mathrm{~mol} \mathrm{~kg}^{-1} \mathrm{NaFSAaq}$. and $21 \mathrm{~mol} \mathrm{~kg}^{-1}$ LiTFSAaq.

electrolytes were higher than those of concentrated LiTFSA aqueous electrolytes. Next, charge-discharge measurements were conducted for activated carbon electrodes in concentrated aqueous electrolytes. $\mathrm{CV}$ curves suggested that aluminum corrosion was severe for positive electrode side. Capacitor reactions were observed for both of positive electrode and negative electrode sides in NaFSA aqueous electrolytes by changing current collectors to titanium foils. In addition, resistances of activated carbon electrodes in NaFSA aqueous electrolytes were much small.

\section{Supporting Information}

The Supporting Information is available on the website at DOI: https://doi.org/10.5796/electrochemistry.20-63001.

\section{Acknowledgments}

This work was financially supported by Kyoto University COI FS study. The activated carbons were produced by Panasonic.

\section{References}

1. A. Nishino, J. Power Sources, 60, 137 (1996).

2. M. Inagaki, H. Konno, and O. Tanaike, J. Power Sources, 195, 7880 (2010).

3. X. Zang, C. Shen, M. Sanghadasa, and L. Lin, ChemElectroChem, 6, 976 (2019).

4. L. Suo, O. Borodin, T. Gao, M. Oleguin, J. Ho, X. Fan, C. Luo, C. Wang, and K. $\mathrm{Xu}$, Science, 350, 938 (2015).

5. Y. Yamada, K. Usui, K. Sodeyama, S. Ko, Y. Tateyama, and A. Yamada, Nat. Energy, 1, 16129 (2016).

6. Y. Yokoyama, K. Miyazaki, T. Fukutsuka, and T. Abe, J. Electrochem. Soc., 165, A3299 (2018).

7. P. Lannelongue, R. Bouchal, E. Mourad, C. Bodin, M. Olarte, S. le Vot, F. Favier, and O. Fontaine, J. Electrochem. Soc., 165, A657 (2018).

8. H. Tomiyasu, H. Shikata, K. Takao, N. Asanuma, S. Taruta, and Y.-Y. Park, Sci. Rep., 7, 45048 (2017).

9. G. Hasegawa, K. Kanamori, T. Kiyomura, H. Kuruta, T. Abe, and K. Nakanishi, Chem. Mater, 28, 3944 (2016).

10. X. Zang, C. Shen, E. Kao, R. Warren, R. Zhang, K. S. The, J. Zhong, M. Wei, B. Li, Y. Chu, M. Sanghadasa, A. Schwartzberg, and L. Lin, Adv. Mater, 30, 1704754 (2018).

11. Y. Yamada, M. Yaegashi, T. Abe, and A. Yamada, Chem. Commun., 49, 11194 (2013).

12. Y. Kondo, Y. Miyahara, T. Fukutsuka, K. Miyazaki, and T. Abe, Electrochem. Commun., 100, 26 (2019). 